\title{
Use of Artificial Dermis and Cultured Epithelial Autograft for Extensive Deep Dermal Burns -A Case Report
}

\author{
Takahiro Ueda, Tomohide Matsushima, Kohei Ichinohashi, Yasuhide Kitazawa \\ Department of Emergency and Critical Care Medicine, Faculty of Medicine, Kindai University, \\ Osaka, Japan \\ Email: kitaz@med.kindai.ac.jp
}

How to cite this paper: Ueda, T., Matsushima, T., Ichinohashi, K. and Kitazawa, Y. (2018) Use of Artificial Dermis and Cultured Epithelial Autograft for Extensive Deep Dermal Burns-A Case Report. Open Journal of Emergency Medicine, 6, 73-81. https://doi.org/10.4236/ojem.2018.64009

Received: September 10, 2018 Accepted: November 27, 2018

Published: November 30, 2018

Copyright ( 2018 by author(s) and Scientific Research Publishing Inc. This work is licensed under the Creative Commons Attribution International License (CC BY 4.0).

http://creativecommons.org/licenses/by/4.0/

\begin{abstract}
In the treatment of extensive burns, cultured epithelial autograph (CEA) became available commercially in Japan from 2009. Based on the 6 years multicenter surveillance data on using CEA for extensive burns, it is reported that using 6:1 split thickness skin graft together with CEA is successful after wound bed preparation for extensive deep dermal burn or patients with deep burn [1].
\end{abstract}

\section{Keywords}

Artificial Dermis, Extensive Burn, Cultured Epithelial Autograft

\section{Background}

This paper reports a rare case where we can get successful outcome clinically and pathologically if the patient was treated strategically using artificial dermis together with CEA without split thickness skin graft after wound bed preparation for extensive deep dermal burn. This paper also reviews the literature and discusses the merits of this technique which may become part of strategy for the treatment of extensive burns. According to the above-mentioned evidence, using 6:1 split thickness skin autograft together with CEA is useful and recommended for deep dermal burn. However, we tried and succeeded another strategy for extensive burns implanting CEA without split thickness skin autograft, using artificial dermis for wound bed preparation. It suggests that this strategy may result in good epithelialization on the wound bed prepared with artificial dermis. 


\section{Case Presentation}

A 21-year-old man was driving his car on a mountain road at $600 \mathrm{~m}$ height above sea level at midnight. After finishing smoking, he threw the cigarette butt out through the car window, however, the wind blew the cigarette butt back into the car. The cigarette butt fell on the blanket in the back seat and caught fire. The fire spread so rapidly that he could hardly escape from the car. He suffered flame burns to his face, back, trunk and limbs. He was unable to call for emergency service and had to walk down the mountain on his own strength before he reached the fire station. He was immediately transferred to our hospital for treatment, ten hours after sustaining burn injury.

Initial physical findings: The patient was alert and oriented. His vital signs showed that the heart rate was 120 beats/min, blood pressure $140 / 100 \mathrm{mmHg}$, body temperature $36.6^{\circ} \mathrm{C}$, and respiratory rate 14 breaths $/ \mathrm{min}$. Contusion on the back of the head and physical injury. And his clothes were burned extensively. The burn wounds were found on his face, neck, back trunk, and limbs. Back trunk and left limb were assessed as deep dermal burn (DDB), and others as superficial dermal burn (SDB) (Figure 1(a)). The total burn area (TBSA) was estimated at 37\%. Sociodemographic and physical characteristics of the patient were summarized in Table 1.

The medical history of the patient was unremarkable. The laboratory blood data were as follows: $\mathrm{WBC} 25.28 \times 10^{3} / \mu \mathrm{L}, \mathrm{Hb} 14.7 \mathrm{~g} / \mathrm{dL}$, platelet $25.6 \times 10^{3} / \mu \mathrm{L}$, total protein $6.0 \mathrm{~g} / \mathrm{dL}$, BUN $23 \mathrm{mg} / \mathrm{dL}$, Creatinine $0.72 \mathrm{mg} / \mathrm{dL}$, AST $132 \mathrm{IU} / \mathrm{L}$, ALT $42 \mathrm{IU} / \mathrm{L}, \mathrm{Na} 137 \mathrm{mEq} / \mathrm{L}, \mathrm{K} 3.9 \mathrm{mEq} / \mathrm{L}$, Prothrombin time $14.6 \mathrm{sec}$, APTT $28.6 \mathrm{sec}$, Antithrombin 97\%. Arterial blood gas analysis (at room air) was as follows; pH 7.35, $\mathrm{PaCO}_{2} 33.4 \mathrm{mmHg}, \mathrm{PaO}_{2} 126.7 \mathrm{mmHg}$, Lactate $2.5 \mathrm{mmol} / \mathrm{L}(22.5$ $\mathrm{mg} / \mathrm{dL}$ ). Chest X-ray and brain CT scan investigation did not show any abnormal findings. The characteristics of the patient's laboratory data were summarized

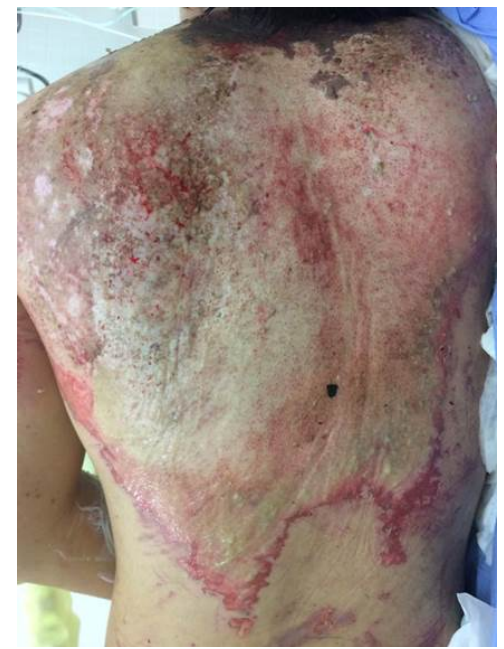

(a)

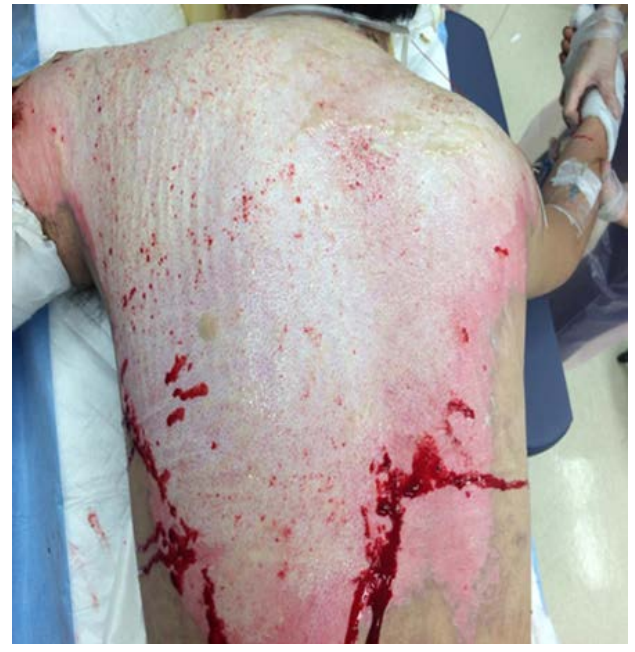

(b)

Figure 1. (a) The appearance of the wounds on admission; (b) The wounds developed infection and necrosis the $10^{\text {th }}$ day after admission. 


\section{in Table 2.}

During emergency treatment, lactate Ringer's solution was infused for fluid resuscitation to maintain urinary output of $0.5-1.0 \mathrm{~mL} / \mathrm{kg} / \mathrm{hr}$ in the first 24 hours after admission. The volume of total fluid resuscitation reached $9020 \mathrm{~mL}$ during the first 24 hours after admission. The serum lactate level was maintained below $2.0 \mathrm{mmol} / \mathrm{L}(18 \mathrm{mg} / \mathrm{dL})$ within the first day of admission. The patient had no complications such as hypovolemic shock or pulmonary edema. The treatment included the application of dimethyl isopropyl azulene ointment with puffing basic fibroblast growth factor (b-FGF; Fibrast Spray ${ }^{\circledR}$; KAKEN Company, Japan)

Table 1. Characteristics of the patient.

\begin{tabular}{cc}
\hline Gender & male \\
Age & 21 years old \\
Employment & unmarried \\
Height & Full-time work \\
Body Weight & $170 \mathrm{~cm}$ \\
Vital signs on admission & $66.6 \mathrm{~kg}$ \\
Blood Pressure & \\
Heart Rate & $140 / 100 \mathrm{mmHg}$ \\
Respiratory Rate $(/ \mathrm{min})$ & $120 / \mathrm{min}$ \\
Body temperature & $12 / \mathrm{min}$ \\
Consciousness on admission & $36.6^{\circ} \mathrm{C}$ \\
\% & clear \\
\hline
\end{tabular}

Table 2. Laboratory data on admission.

\begin{tabular}{cc}
\hline $\mathrm{WBC}$ & $25,280 / \mu \mathrm{L}$ \\
$\mathrm{Hb}$ & $14.7 \mathrm{~g} / \mathrm{dl}$ \\
$\mathrm{Plt}$ & $25.6 \times 10^{3} / \mu \mathrm{L}$ \\
$\mathrm{Na}$ & $137 \mathrm{mEq} / \mathrm{L}$ \\
$\mathrm{K}$ & $3.9 \mathrm{mEq} / \mathrm{L}$ \\
$\mathrm{AST}$ & $132 \mathrm{IU} / \mathrm{L}$ \\
$\mathrm{ALT}$ & $42 \mathrm{IU} / \mathrm{L}$ \\
$\mathrm{TP}$ & $6.6 \mathrm{~g} / \mathrm{dL}$ \\
$\mathrm{BUN}$ & $23 \mathrm{mg} / \mathrm{dL}$ \\
$\mathrm{Creatinin}$ & $0.72 \mathrm{mg} / \mathrm{dL}$ \\
$\mathrm{PT}$ & $14.6 \mathrm{sec}$ \\
$\mathrm{APTT}$ & $28.6 \mathrm{sec}$ \\
$\mathrm{PH}$ & $126.7 \mathrm{Torr}$ \\
& $33.4 \mathrm{Torr}$ \\
& Arterial Blood Gas $($ room air $)$ \\
& 7.35 \\
&
\end{tabular}


on the wounds after washing, every day. The use of CEA was considered and decided with the patient on the day of admission. JACE ${ }^{\mathbb{B}}$ (Japan tissue engineering company Aichi Japan; J-TEC) is only certified as CEA by health insurance in Japan. We harvested full thickness healthy skin from unburned areas (right lower abdomen) which measured $2 \mathrm{~cm} \times 4 \mathrm{~cm}$ in size under local anesthesia on the first day of admission and ordered to prepare $\mathrm{JACE}^{\circledR}$. In clinical course, the wounds on his hands, back and left upper extremity were epithelized well. However, the wound on his back trunk, which had been diagnosed as DDB, deteriorated into full thickness burn with necrotic tissue on the 9th day of admission (Figure 1(b)). We performed surgical debridement on this wound on the $10^{\text {th }}$ day of admission. All necrotic tissues were removed with tangential excision by hand dermatome until we could find blood circulation. After the surgery, we implanted artificial dermis (Integra ${ }^{\circledR}$ Integra; Life Sciences company NJ, USA) on the wound, and applied the dressings with non-adhering contact gauze (SI-mesh $^{\circledR}$; ALCARE Tokyo, Japan) (Figure 2(a)). Clinical course after first

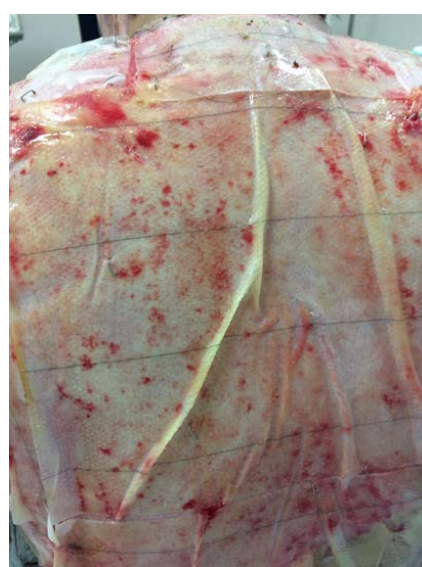

(a)

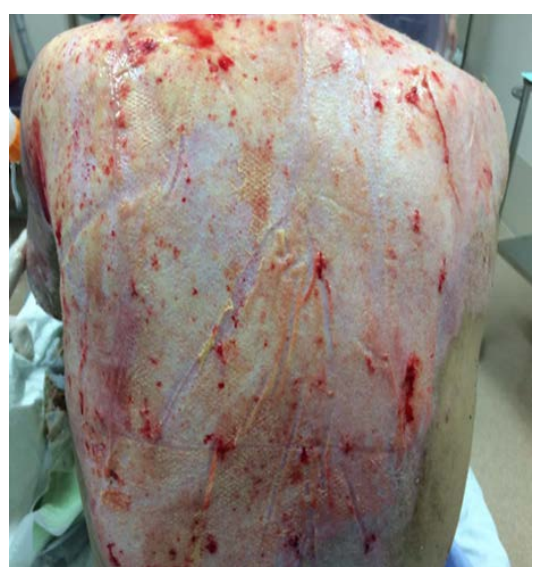

(b)

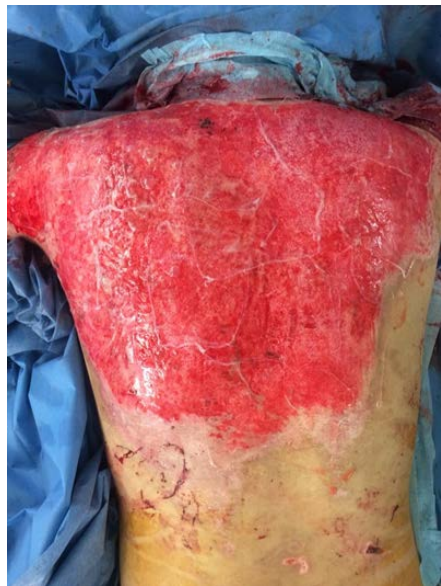

(c)

Figure 2. (a) Artificial dermis (Integra $\left.{ }^{(}\right)$placed on the wounds after tangential excision; (b) Reconstruction of dermis in macroscopic on the $20^{\text {th }}$ day after admission; (c) Implanted independent CEA on the wounds after wounds bed preparation, on the $28^{\text {th }}$ day after admission. 
operation was very good and there were no complications. On $28^{\text {th }}$ day of admission, we decided to implant only CEA (JACE ${ }^{\circledR}$ ) without using split thickness skin autograft on his back trunk (Figure 2(b)). On $10^{\text {th }}$ day after grafting, the wound was evaluated as good condition and epithelized very well (Figure 3(a)). The patient needed no skin-harvesting for split thickness auto-graft. No remarkable complications were observed during admission. The patient was discharged from the hospital, 54 days after admission.

We followed up the patients for 200 days after admission (146 days after discharge at the department of outpatient). The wound on his back was reassessed at out-patient clinic 90 days after discharge and evaluated as point 10 in the Vancouver Scar Scale (VSS) and point 13 in the Manchester Scar Scale (MSS). Two hundred days after discharge, the wound on his back was assessed as point 4 and in VSS and point 7 in MSS respectively (Figure 3(b), Figure 3(c)). The patient had not appealed any complaints of the wounds, and the hypertrophic scar of his back trunk had been improved gradually and disappeared finally.

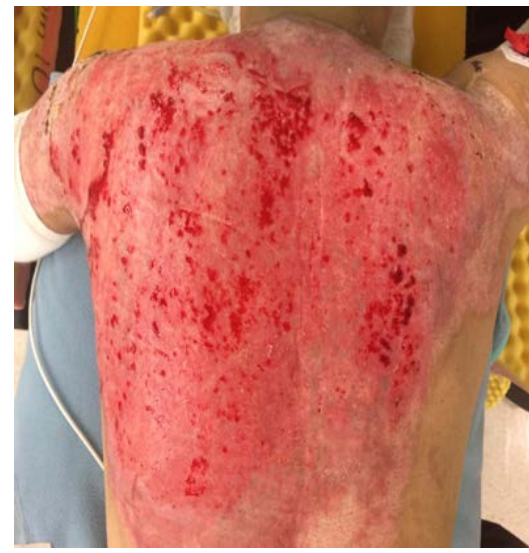

(a)

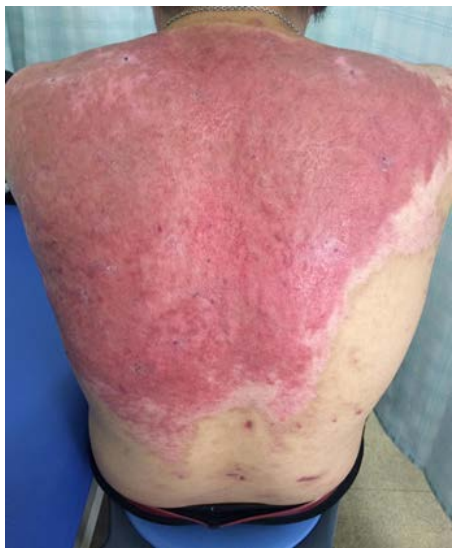

(b)

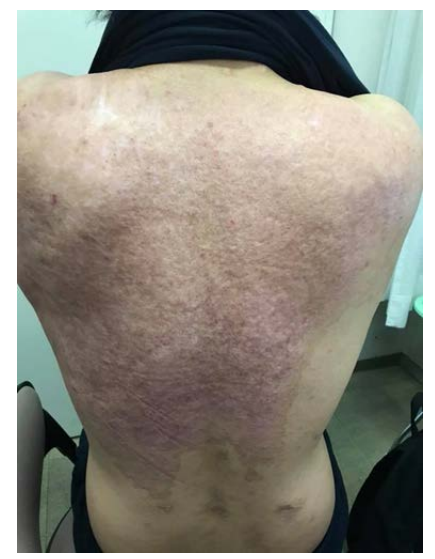

(c)

Figure 3. (a) The appearance of the operated wound on the post-operative 10th day. The wounds implanted CEA were well epithelized; (b) The appearance of the operated wound on the post-operative $62^{\text {nd }}$ day. The wounds showed reddish, but no signs of abnormal granulation; (c) The appearance of the operated wound on the post-operative $172^{\text {nd }}$ day. The reddish of the wounds was improved and no sign of hypertrophic scar and keloid. 


\section{Discussion}

Since early 1980s, CEA has been used clinically for patients with extensive burns. CEA "JACE" ${ }^{\circledR}$ " has been recognized as a treatment for extensive burns. JACE ${ }^{\circledR}$ has been certified by the public health insurance since 2009 in Japan. Prior to the certification, we employed the procedure using $\mathrm{JACE}^{\circledR}$ combined with 6:1 split thickness skin graft, for the first time in Japan in 2006. It was very hard to make treatment plans for extensive burns using CEA, because we had few clinical evidences on the merits of using CEA. During this time, the treatment methodology for wounds of full thickness burn, was to implant with artificial dermis to reconstruct the dermis like normal tissue after debridement, followed by CEA implant combined with 6:1 split thickness skin graft. Matsumura [1] et al. described that wound bed preparation before using CEA for extensive burns helps with epithelization. Vigani [2] et al. suggested extensive deep burns should be implanted with CEA combined split thickness skin graft after reconstructed dermis with artificial dermis. Bishra [3] et al. reported that CEA was useful for extensive deep burns but revealed no evidence in the treatment of deep dermal burns. Wood et al. reported a critical review of literature which evaluated the use of CEA in the treatment of massive deep burn injuries. In the above quoted literature, the level of evidence to support the use of CEA for massive burn injuries was available including 31 randomized controlled trials and case studies, but these reviews did not show the use of CEA for DDB [4].

In our case, we used artificial dermis to reconstruct dermis and implanted CEA onto the mixed full thickness burn (deep burn; DB) and DDB wounds. Since the patient was very young in age, the wound bed preparation with artificial dermis appears to have grown like normal tissue. This prevented the complications of graft donor sites and avoided the combination of split-thickness skin graft with CEA implantation [5]. The probable reason why independent CEA is useful for epithelization of the mixed DB and DDB wounds is that artificial dermis may well stimulate the survived dermis cells in the wounds to regenerate.

We implanted Integra ${ }^{\circledR}$ artificial dermis onto the wound after debridement which is composed of bi-layered dermal substitute. The first layer is a matrix of bovine collagen and shark chondroitin 6-sulfate, cross linked with glutaraldehyde. The second layer is silicone membrane made of thin polysiloxane, which control fluid and heat loss and acts as a temporary epidermis. Integra ${ }^{\circledR}$ contains $70-200 \mu \mathrm{m}$ pores, water and wound leachate can easily discharge from it. The cross-link structure of collagen layer makes horizontal cell movement easier and prompt soaking of dermis cell smoothly and quickly to form dermis tissue [6] [7]. One report evaluated the use of Integra ${ }^{\circledR}$ in the treatment of extensive burns and showed that wound healing would improve enouch with good epithelization if there is no sepsis [8]. It suggests that the implantation of CEA does not always need split thickness skin graft if the recipient site has been well reconstructed as dermis like tissue. 
Based on this report, implanting independent CEA on the well reconstructed dermis would be effective for successful epithelization. Pathological studies on the use of Integra ${ }^{\circledR}$, was originally targeted for damaged foot skin due to ulcer and was not about treatment of burn injury. This study showed vascularization and syncytial fibroblast movement into wound that replaced Integra ${ }^{\circledR}$ hence contributing to the formation of epidermis in microscopic examination [9]. Our treatment strategy was based on this rationale.

Immunohistochemical analysis for our case is shown in Figure 4, comparing the use of artificial dermis and without artificial dermis, stained by anti-laminin and anti-collagen IV. The result shows that wound replaced with artificial dermis had greater amount of basement membrane and basal cell compared to slide without artificial dermis. This suggests that artificial dermis grew natural dermal tissue. Some reports such as Guofeng [10] et al. and Van der Wal [11] et al. seem to support our discussion.

Basement membrane (basal cell layer) consist of collagen IV and laminin produced from basal cell. Basal cell is the stem cell of keratinocytes that forms basal cell, and basement membrane support the development of epidermal cells. This implies that implanting independent CEA can progress to epithelization of mixed DB and DDB wounds after reconstruction with artificial dermis. Therefore, good wound bed preparation with artificial dermis will produce successful healing process. The independent CEA applied on the burned wound can

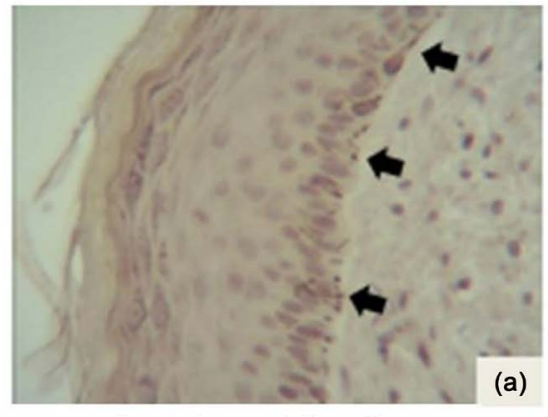

Artificial dermis (+); Collagen 4

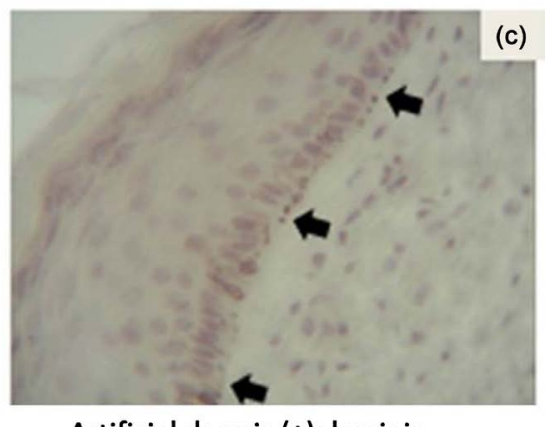

Artificial dermis (+); laminin

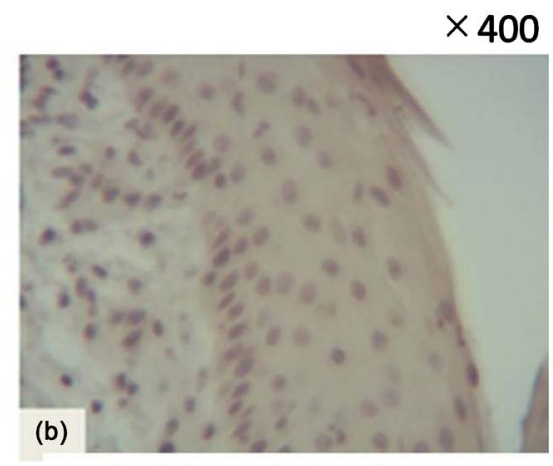

Artificial dermis ( - ); Collagen 4

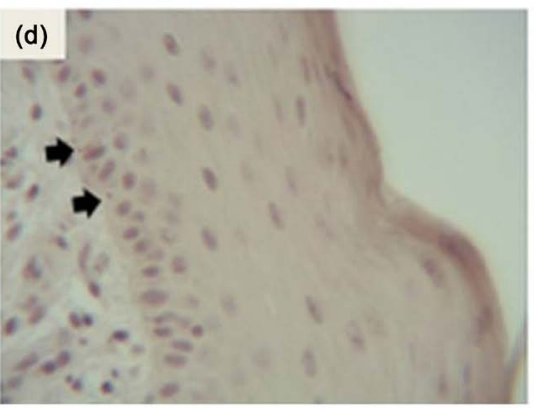

Artificial dermis (-); laminin

Figure 4. Immunohistochemical aspects of wounds treated with artificial dermis ((a) \& (c)) and without artificial dermis ((b) \& (d)); anti-collagen 4 staining ((a) \& (b)) and anti-laminin staining $((\mathrm{c}) \&(\mathrm{~d}))$. Both collagen 4 and laminin were well produced on basal membranes and basal cells in the tissue treated with artificial dermis (pointed by allows). 
promote the surviving dermis to epithelize. Further, it reduces the complication of hypertrophic scar since there is no need for harvesting dermis from normal skin.

In cases of patients with extensive skin burns with very limited donor sites, our strategy using CEA without autograft appears to be successful way to treat skin burns and could be considered as an alternative option. We would like to investigate further. Based on this experience, we propose the present strategy instead of split skin graft for clinical treatment of skin burned patients.

\section{Conclusion}

We report and suggest an additional strategy for deep dermal burns; the independent CEA (only) implantation can result in good epithelization after wound bed preparation with artificial dermis.

\section{Conflicts of Interest}

The authors declare no conflicts of interest regarding the publication of this paper.

\section{References}

[1] Matsumura, H., Matsushima, A., Ueyama, M. and Kumagai, N. (2013) Application of the Cultured Epidermal Autograft "JACE ${ }^{\circledR}$ " for Treatment of Severe Burns: Results of a 6-Year Multicenter Surveillance in Japan. Journal of the International Society for Burn Injuries, 42, 769-776. https://doi.org/10.1016/j.burns.2016.01.019

[2] Vigani, A. and Culler, C.A. (2017) Systemic and Local Management of Burn Wounds. Veterinary Clinics of North America: Small Animal Practice, 47, 1149-1163. https://doi.org/10.1016/j.cvsm.2017.06.003

[3] Atiyel, B.S. and Costagliola, M. (2007) Cultured Epithelial Autograft (CEA) in Burn Treatment: Three Decades Later. Journal of the International Society for Burn Injuries, 33, 405-413. https://doi.org/10.1016/j.burns.2006.11.002

[4] Wood, F.M., Kokybaba, M.L. and Allen, P. (2006) The Use of Cultured Epithelial Autografts in the Treatment of Major Burn Injuries: A Critical Review of the Literature. Journal of the International Society for Burn Injuries, 32, 395-401. https://doi.org/10.1016/j.burns.2006.01.008

[5] Danielsen, P.L., Jorgensen, L.N., Jørgensen, B., Karlsmark, T. and Ågren, M.S. (2013) Erythema Persist Longer than One Year in Split-Thickness Skin Graft Donor Sites. Acta Dermato-Venereologica, 93, 281-285. https://doi.org/10.2340/00015555-1455

[6] Chou, T.D., Chen, S.L., Lee, T.W., et al. (2001) Reconstruction of Burn Scar of the Upper Extremities with Artificial Skin. Plastic and Reconstructive Surgery, 108, 378-384. https://doi.org/10.1097/00006534-200108000-00015

[7] Lee, L.F., Porch, J.V., Splender, W. and Garner, W.L. (2008) Integra in Lower Extremity Reconstruction after Burn Injury. Plastic and Reconstructive Surgery, 121, 1256-1262. https://doi.org/10.1097/01.prs.0000304237.54236.66

[8] Heimbach, D.M., Warden, G.D., Luterman, A., et al. (2003) Multicenter Post Approval Clinical Trial of Integra ${ }^{\circledR}$ Dermal Regeneration Template for Burn Treatment. Journal of Burn Care and Rehabilitation, 24, 42-48. 
[9] Lucariello, A., Cinelli, M., De Novellis, A., Nikolopoulos, C., Esposito, V. and Guerra, G. (2014) Effect of the Combined Use of a Dermal Substitute with a Cleaning Process in the Simulation of Autologous Skin: A Pilot Study. In Vivo, 28, 639-644.

[10] Huang, G., Ji, S., Luo, P., et al. (2012) Evaluation of Dermal Substitute in a Novel CO-Transplantation Model with Autologous Epidermal Sheet. PLoS ONE, 7, e49448. https://doi.org/10.1371/journal.pone.0049448

[11] Van der Wal, M.B., Vloemans, J.F., Tuinebreijer, W.E., et al. (2012) Outcome after Burns: An Observational Study on Burn Scar Maturation and Predictors for Severe Scarring. Wound Repair and Regeneration, 20, 676-687.

https://doi.org/10.1111/j.1524-475X.2012.00820.x 